\title{
Presencia de Arthur Rimbaud en dos revistas peruanas*
}

CAMILO FERNANDEZ COZMAN

I

Asombrosa la modernidad que asoma en el discurso poético de Rimbaud. Enorme ha sido su influencia en el cauce de la poesía de este siglo. El temple iconoclasta, desacralizador de Rimbaud anticipa la des-mitificación de la estética clásica, propugnada por los poetas vanguardistas curopeos. El autor de Una temporada en el infierno es indudable antecedente del surgimiento del surrcalismo, como movimiento de ruptura de los esquemas clásicos de belleza. La presencia del discurso del otro en "El barco cbrio" o "Alquimia del espíritu" anticipa las exploraciones surrealistas del mundo de lo inconsciente.

La mezcla de géneros, que se actualiza en la obra de Rimbaud, es aún más abrupta que la prepugnada per el romanticismo y anuncia la crisis del concepto tradicional de género literario como entidad absolutamente diferenciada. Rimbaud compone poemas en prosa, fragmenta su discurso, utilizando varias voces que parlamentan entre sí. Todo ello presagia la narratividad totalizante y polifónica de los poetas contemporáneos de habla inglesa. ¿Estamos, acaso, en presencia de una obra que en su complejidad resume el abanico de posturas de la literatura contemporánea? Evidentemente que sí. La novela lírica de Proust con su típico fragmentarismo, o el prosaísmo de los poetas beatnik han sido columbrados por el heraldo, y ese mensajero de la modernidad es Rimbaud.

* Este texto transcribe con ligeras variantes la ponencia presentada en el Instituto Raúl Porras Barrenechea en noviembre de 1991, en conmemoración del centenario de la muerte de Arthur Rimbaud. 
Pero no sólo eso. La conciencia crítica de Rimbaud, como la de Baudelaire, anticipa la rica visión de poetas que practican la crítica literaria, como T.S. Eliot, Ezra Pound u Octavio Paz. Reflexionar, comprender la modernidad son oficios insoslayables del escritor, parece decirnos el Rimbaud de "Cartas del vidente". Sentimiento de poeta y pensamiento analítico pueden compaginarse. El mito y el logos no constituyen realidades irreconciliables. Las ciencias humanas y el rigor algún día necesitarán de la metáfora, sugiere Roland Barthes en uno de sus más celebrados ensayos ${ }^{1}$.

En Las flores del mal ya habían aparecido algunos tópicos que van a ser desarrollados por Rimbaud: la estética de lo feo, que implica un rechazo de los ideales clásicos de belleza basados en la armonía; el satanismo o culto al demonio visible en el poema "Letanías a Satán", que implica una desacralización de prototipos cristianos; el fragmentarismo discursivo, entre otros elementos que se manifiestan en el libro de Baudelaire, quien empleaba detalles grotescos para retratar la vida de seres expulsados del concierto de la sociedad oficial ${ }^{3}$. Aparece la multitud que, según Walter Benjamin ${ }^{4}$, provoca una especie de shock neurótico en el poeta, quien se ve obligado a percibir las asombrosas contradicciones de una civilización dominada por la técnica: una industrialización que conduce al decir de Baudelaire, a una "progresiva decadencia del alma " a una "strofia del espíritu".

La modernidad tiene sus bemoles. Baudelaire y Rimbaud lo sabían. El hombre conviértese en una pieza de una inmensa maquinaria que camina ciega hacia su propia destrucción. La rutina alienante agobia; los mitos de la civilización tecnológica son asumidos acríticamente, y la deshumanización impone su reinado. La poesía se rebela, busca nuevas sendas, quiere liberar al lenguaje del yugo del

${ }^{1}$ Roland Barthes, El susurro del lenguaje. Más allá de la palabra y la escritura. Barcelona, Paidós, 1987, pp. 17 y ss.

${ }^{2}$ Cf. Charles Baudelaire, Las flores del mal. Traducción y prólogo de Nydia Lamarque. Buenos Aires, Losada, 1980, pp. 194 y ss.

${ }^{3}$ Cf. "A una mendiga pelirroja". En: op. cit pp. 136 y ss.

${ }^{4}$ Walter Benjamin, Poesia y capitalismo. Iluminaciones II, pp. 130 y ss.

${ }^{5}$ Citado por Hugo Friedrich, Estructura de la lírica moderna. Madrid, Seix Bartal, 1959, p. 60. 
pensamiento lógico de estirpe racionalista-cartesiana y devolver la inocencia a las palabras. Verdaderamente todo un reto, el cual va a ser asumido por el joven Rimbaud, desde la locuacidad hasta el inocultable silencio.

\section{II}

Ahora sí corresponde preguntarse cómo ha sido la acogida que ha tenido la poesía de Rimbaud en el Perú. Debo advertir que no es mi propósito el de presentar una historia de la recepción de la poesía de Rimbaud en nuestro país. Simplemente quiero ilustrar la acogida que suscitó en dos de las revistas culturales peruanas más importantes de este siglo: Amauta, dirigida por José Carlos Mariátegui; y Las Moradas, cuya dirección estuvo a cargo de Emilio Adolfo Westphalen.

Empecemos por Amauta. En el N ${ }^{\circ} 21$ (febrero-marzo de 1929) se le tributa un homenaje a José María Eguren. Allí aparece un artículo del propio Mariátegui, cuyo título es "Contribución a la crítica de Eguren". Después de calificar al poetar de Simbólicas de cosmopolita, Mariátegui afirma:

"Se pretende que en Eguren hay trazas especiales de la influencia de Rimbaud. Mas el gran Rimbaud era, temperamentalmenite tæantítesis de Égurañ Nietzscheano, agónico, Rimbaund habría exćlamảdocconeel Guillén de Deucalion: 'Yo he de ayudar al Diablo a conquistar el cielo' [...] Mílite de la Comuna, Rimbaud tenía una psicología de aventurero y de revolucionario. "Hay que ser absolutamente moderno", repetía. Y para serlo dejó a los veintidós años la literatura y París. A ser poeta en París prefirió ser pioneer en Africa. Su vitalidad excesiva no se resignaba a una bohemia citadina y decadente, más o menos verleniana. Rimbaud, en una palabra, era un ángel rebelde ${ }^{6}$.

En la cita se evidencia que Mariátegui leía las obras de Rimbaud desde una perspectiva latinoamericana. Por eso, compara su actitud con la de un poeta latinoamericano: Alberto Guillén,

${ }^{6}$ José Carlos Mariátegui, 7 ensayos de interpretación de la realidad peruana. Lima, Biblioteca Amauta, 1982, p. 297. Este texto de 7 ensayos... reproduce en gran medida el aparecido en el $N^{\circ} 21$ de Amauta. 
continuador de las propuestas del iconoclasta movimiento "Colónida". Mariátegui resalta el carácter nietzscheano de Rimbaud, porque el poeta francés era un vitalista, debido a su postura desmitificadora, que lo hermana al autor de Así hablaba Zaratustra. No se debe olvidar que Mariátegui era un gran admirador de Nietzsche. En la "Advertencia" a 7 ensayos de interpretación de la realidad peruana, Mariátegui afirmaba:

Y su algún mérito espero y reclamo que me sea reconocido es el de -también conforme un principio de Nietzsche- meter toda mi sangre en mis ideas ${ }^{7}$.

Hay un gran lazo entre Rimbaud y Nietzsche, porque ambos desacralizan los mitos de la civilización occidental, fusionan el logos con el mito y anuncian los tiempo modernos. La comparación de Mariátegui, por consiguiente, me parece justa.

Considera Mariátegui que Rimbaud es agónico. Es necesario precisar que el concepto de agonía, empleado por el pensador peruano, es unamuniano. Vale decir, agonía significa lucha. Por eso, la agonía de Rimbaud delimita su larga travesía contra una sociedad tecnológica que atrapa al hombre en sus redes. Pero también evidencia la lucha de Rimbaud con las palabras, a fin de que su corpus poético actualice una ruptura de los sistemås versales eradicionales, enriqueciendo el discurso con la orquestación de divètsas voces,opues la poesía excesivamente subjetivista es insípida para Rimbaud ${ }^{8}$.

Mariátegui piensa que Rimbaud posee "una psicología de aventurero y de revolucionario". En este caso, Mariátegui entiende la "aventura" asociada a la "revolución" o al cambio de estructuras. Me parece que aquí se hace referencia a la búsqueda de nuevas formas expresivas, a esa experimentación aventurera que se respira en la obra de Rimbaud. En este sentido, Rimbaud es un "ángel rebelde" que nos plantea a los latinoamericanos la urgente posibilidad de transformar

${ }^{7}$ Ibid., p. [11].

8 "su poeśa subjetiva será siempre horriblemente insípida. Un día, espero, muchos esperan lo mismo,- veré en su principio ¡La poesía objetiva, la veré más sinceramente de lo que usted lo haría!" Rimbaud, Arthur. "A Georges Izambard". En: El barco ebrio y otros poemas. Lima, UNMSM, Unión Latina y Embajada de Francia, 1991, p. 64. 
las estructuras estéticas y económicas de las sociedades subdesarrolladas, por eso Rimbaud escribe:

Seré un trabajador: ¡es la idea que me retiene cuando las cóleras locas me impulsan hacia la batalla de París donde, sin embargo, tantos trabajadores mueren mientras le escribo!?.

Ahora corresponde el turno a Las Moradas, publicación que significó una decisiva apertura a las distintas vertientes del pensamiento europeo. En efecto, el contexto ha variado sustancialmente, en relación al de la revista Amauta. No obstante, la amplitud de criterio de Westphalen nos recuerda a la de José Carlos Mariátegui. En el $N^{\circ} 2$ de Las Moradas (julio-agosto de 1947), aparece un artículo del poeta Jorge Eduardo Eiclson, cuyo título es "Rimbaud y la conducta fundamental". Eielson comienza con un intento de precisión histórica:

A la luz de 1947, la palabra de Rimbaud promueve secretas digresiones ${ }^{10}$.

La huella del contexto se percibe en la influencia del existencialismo en este ensayo, el cual marca lazos entre Rimbaud y aquella corriente de pensamiento. Sin embargo, Rimbaud

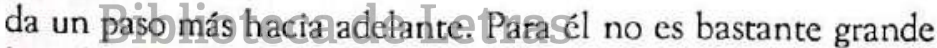
la redondez debplaneta, lcuyo suelo no encuentra digno de su atroz actividad [...] Tiene demasiada amplitud para imaginarse una causa trascendente fuera de su alcance; se limita a confirmar su inmensa libertad al servicio de un futuro estado universal ${ }^{11}$.

Nuevamente, la idea de que Rimbaud es el heraldo de la modernidad; pero, esta vez, asociada a la libertad. La "atroz actividad" hace referencia al difícil oficio de poeta-vidente que contempla el futuro. La obra artística anuncia propuestas teóricas posteriores. ¿Acaso la idea vallejiana de la solidaridad como una comunidad de todos no anticipa el nacimiento de la teología de la liberación? La preeminen-

${ }^{9}$ Loc. cit.

${ }^{10}$ Jorge Eduardo Eielson, "Rimbaud y la conducta fundamental". En: Las Moradas, vol. I, N², Lima, julio-agosto de 1947, p. [183].

${ }^{11}$ Ibid., p. 185. 
cia que tienen los discursos del loco y del ebrio en la poesía de Rimbaud anticipa en cierto modo la propuesta filosófica de Michel Foucault. Se trata, pues, de discursos marginados por las estructuras de poder. El poeta ejercita su libertad creadora a través de la locura: "La historia de una de mis locuras" ${ }^{12}$, asevera Rimbaud casi presagiando el título de uno de los libros de Foucault ${ }^{13}$.

Pero también Eielson como poeta-crítico está asumiendo la sugerencia de Rimbaud, en el sentido de que el poeta debería tener una capacidad de discernimiento, que le permita ubicarse con propiedad y rigor en su propio contexto histórico. Creo percibir la influencia de Rimbaud en Habitación en Roma ${ }^{14}$, uno de los grandes poemarios de Eielson. En principio, el título del poema inicial ("Elegía blasfema para los que viven en el barrio de San Pedro y no tienen qué comer") evidencia una postura desacralizadora, una "blasfemia" que nos recuerda a algunos pasajes de Una temporada en el infiemo. No es el momento de analizar la poesía de Eielson, pero quisiera dejar constancia de la gran coherencia que existe, en muchás ocasiones entre la praxis poética y los ensayos de Eielson. En ambos campos, asoma la figura de Arthur Rimbaud.

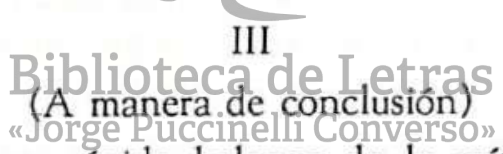

Eielson hace un rápido balance de la crítica francesa sobre Rimbaud y rechaza los aportes que no son significativos. Su condición de latinoamericano le permite un distanciamiento crítico para ver ciertos elementos de la obra de Rimbaud, que pasan desapercibidos a algunos estudiosos europeos. Por ejemplo, Eielson pone énfasis en la formulación de una nueva utopía vislumbrada por el vidente Rimbaud.

Mariátegui, por su parte, señala puntos comunes entre Rimbaud y Alberto Guillén. Así, asume una óptica latinoamericana para repensar aspectos de la cultura europea.

12 Arthur Rimbaud, Ob. cit., p. 53.

${ }^{13}$ Me refiero al libro de Foucault, cuyo título es Historia de la locura en la época clásica. México, Fondo de Cultura Económica, 1967.

${ }^{14}$ Jorge Eduardo Eielson, Poesía escrita. Lima, INC, 1976, pp. [165] y ss. 
Pienso que está abierta la posibilidad de realizar una lectura latinoamericana de los maestros de la literatura europea. Kafka o Proust, por ejemplo, podrían ser leídos desde una óptica que reconozca nuestra propia identidad cultural y especificidad histórica.

El "Yo es otro", dice Rimbaud. El poeta habla por y a través de los otros:

"Los sufrimientos son enormes -afirma Rimbaud-, pero es necesario ser fuerte, haber nacido poeta, yo me he reconocido poeta. De ninguna manera es mi falta. Es falso decir: Yo pienso. Se debería decir: Se me piensa. -Perdón por el juego de palabras"15.

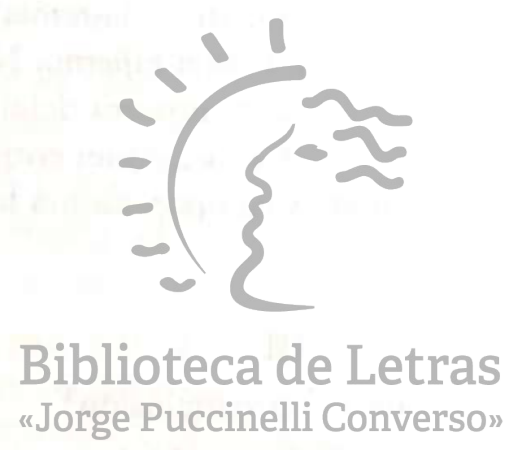

${ }^{15}$ Arthur Rimbaud, Ob. cit., p. 64. 